\title{
Identifying Heat Tolerant Rice Genotypes under Field Conditions
}

\author{
A.A. Abd Allah, Shimaa A.Badawy*, I.M.O. Elrewainy and \\ A.M. Elkhtyar \\ Rice Research \& Training Center, Agricultural Research Center, \\ Sakha and *Agronomy Department, Faculty of Agriculture, \\ Kafrelsheikh University, Kafrelsheikh, Egypt.
}

\begin{abstract}
EVELOPMENT OF some rice genotypes tolerant to heat stress EVELOPMENT OF some rice genotypes tolerant to heat stress
during different growth stages is one adaptation strategy for mitigating the negative effects of global warming. To this end, assessing the trait variation and identifying suitable genetic donors is essential. We assessed the genetic variability for heat tolerance-related traits in 20 diverse cultivars under heat stress (HS) and non-stress conditions (NS). The experiments were laid out in a randomized complete block design with three replications in New Valley Research Station (south of Egypt) as heat stress conditions and Sakha Research Station (north of Egypt) as non-stress conditions to assess the effects of high temperature during vegetative, reproductive and ripening growth phases on its growth, yield and yield components. Considerable variation of cultivars was observed among genotypes under HS and NS environments. Physiological parameters identifying heat tolerant variety is a necessary and is reliable and superior to all the screening procedures. High temperature induces sterility, if the sensitive physiological processes are affected. The average grain yield decreased by $22 \%$ under HS relative to the NS environment, with high temperature having the greatest effect on spikelets and pollens sterility in New Valley conditions. Higher spikelet sterilities ranging between $14 \%$ and $80 \%$ were noted under HS than under NS (10\% and $18 \%)$, while pollens sterility was also higher under HS (15\% and $54 \%)$ than under NS (16\% and $34 \%)$. Grain yield was negatively correlated with pollen and spikelet sterility under both HS and NS. Potential donors identified based on at least one trait included ARC11094, Pinulupot1, Tupa729, Shinriki, Kameji and Giza 178.
\end{abstract}

Keywords: Rice, Heat tolerance, High temperature, Spikelet fertility, Grain yield.

The rise in atmospheric temperature causes detrimental effects on growth, yield, and quality of the rice crop by affecting its phenology, physiology, and yield components (Singh, 2001; Collard \& Mackil, 2008 and Craufurd et al., 2003). The sensitivity of rice to high temperature varies with growth phase, an increase in day/night temperature, and genotype (Yoshida et al., 1981; Singh, 2001 and 
Craufurd et al., 2003). The unusual rise in atmospheric temperature during different growth phases differentially affects rice growth and productivity.

Also, global climate change will impact on yield potential and production through changed weather and atmospheric carbon dioxide concentration, affecting crop growth and development, irrigation demand and the supply of irrigation water. Analysis of the effects of climate change on yield potential and its consequences for yield gaps and water resource requirements, requires the application of rigorously tested and validated crop models, calibrated for key species and current varieties (Kijne, 2003).

Rising temperatures brought about by climate change will negatively impact rice (Oryza sativa L.) production. The crop grows optimally between $20^{\circ} \mathrm{C}$ to $35^{\circ} \mathrm{C}$ and increases in ambient temperature higher than $10-15^{\circ} \mathrm{C}$ over the optimum growing temperature can constitute heat stress (Wahid et al., 2007). Heat injury occurs at the vegetative and reproductive stages when rice is exposed to $>35^{\circ} \mathrm{C}$ and this high temperature results in high spikelet sterility (Yoshida et al., 1981). Even just an hour of exposure to heat stress at anthesis could induce sterility and result in grain yield reduction (Jagadish et al., 2007). The sterility mainly results from reduced anther dehiscence, low pollen production, and low numbers of germinating pollen grains on the stigma (Matsui et al., 2001 and Prasad et al., 2006). Relative humidity (RH) modifies the effect of heat stress-induced sterility in rice with high $\mathrm{RH}$ coupled with high temperature during anthesis adversely affecting spikelet fertility and, conversely, with sterility decreasing significantly with decreasing RH (Weerakoon et al., 2008). Mohammed \& Tarpley (2009) noted that high night temperatures also reduce rice yield and quality.

The development of rice varieties able to tolerate temperatures $>35^{\circ} \mathrm{C}$ during flowering becomes imperative, especially with projected scenarios on global warming. However, genetic diversity for rice heat tolerance is not well-characterized making varietal improvement initially difficult. In fact, rice breeding programs have so far ignored direct selection for heat tolerance. Spikelet sterility (Prasad et al., 2006) and high pollen shedding (Mackill \& Coffman, 1983) have been suggested as selection criteria in breeding heat-tolerant rice. (Satake \& Yoshida, 1978) recommended a screening temperature of $35^{\circ} \mathrm{C}$ to eliminate heat-susceptible materials and $38^{\circ} \mathrm{C}$ for selecting heat-stress tolerant lines.

Two approaches may be used in breeding heat-tolerant rice: (1) Selecting for heat tolerance at flowering and (2) Changing rice flowering time to an earlier and thus cooler period in the day (Redona et al., 2007).

\section{Materials and Methods}

\section{Trials and locations}

Two types of field trials, i.e. heat stress (HS) and non-stress conditions (NS) were conducted at the farm of the Rice Research and Training Center, Sakha,

Egypt. J. Agron. 33, No. 2 (2011) 
Kafrelsheikh, at the northern part of the Nile Delta, Egypt as a non-stress condition (NS) and at the farm of New Valley Research Station, at the southern part of Egypt as a heat condition (HS). Heat stress trials were planted such that the flowering of genotypes occurred during the hottest period of the year (August). Non-stress trials were planted during the normal summer season, with flowering during August and September. Both heat stress and non-stress trials were conducted during 2009 and 2010 under irrigated conditions. Seeds were grown directly in the field under New Valley conditions with a temperature setting of $28^{\circ} \mathrm{C}$ at $40^{\circ} \mathrm{C}$ day/night as the average and relative humidity from 60 to $70 \%$ at flowering (Table 1 ).

TABLE 1. Monthly average of air temperature and relative humidity in the growing seasons at Sakha and New Valley Research Stations (ARC, New Valley Research Stations, 2009 and 2010 seasons).

\begin{tabular}{|c|c|c|c|c|c|c|c|c|c|c|c|c|}
\hline \multirow{4}{*}{ Month } & \multicolumn{6}{|c|}{ Sakha, Kafrelsheikh } & \multicolumn{6}{|c|}{ New Valley } \\
\hline & \multicolumn{3}{|c|}{2009} & \multicolumn{3}{|c|}{2010} & \multicolumn{3}{|c|}{2009} & \multicolumn{3}{|c|}{2010} \\
\hline & \multicolumn{2}{|c|}{$\begin{array}{c}\text { Air } \\
\text { Temp. }\end{array}$} & \multirow{2}{*}{$\begin{array}{c}\text { RH } \\
\% \\
\end{array}$} & \multicolumn{2}{|c|}{$\begin{array}{c}\text { Air } \\
\text { Temp. }\end{array}$} & \multirow{2}{*}{$\begin{array}{c}\text { RH } \\
\%\end{array}$} & \multicolumn{2}{|c|}{$\begin{array}{c}\text { Air } \\
\text { Temp. }\end{array}$} & \multirow{2}{*}{$\underset{\%}{\mathbf{R H}}$} & \multicolumn{2}{|c|}{$\begin{array}{c}\text { Air } \\
\text { Temp. }\end{array}$} & \multirow{2}{*}{$\begin{array}{c}\text { RH } \\
\%\end{array}$} \\
\hline & Max & Min & & Max & Min & & Max & Min & & Max & Min & \\
\hline May & 28.7 & 12.6 & 63.3 & 29.6 & 14.4 & 56.1 & 35.7 & 20.9 & 26.3 & 38.3 & 21.2 & 25.0 \\
\hline June & 33.6 & 19.0 & 62.5 & 33.5 & 19.3 & 61.4 & 40.6 & 24.6 & 22.3 & 41.8 & 25.3 & 24.3 \\
\hline July & 33.0 & 20.2 & 65.3 & 32.0 & 20.0 & 65.1 & 41.3 & 26.1 & 26.7 & 40.5 & 26.7 & 23.3 \\
\hline August & 32.4 & 19.0 & 66.3 & 34.0 & 21.2 & 67.9 & 39.7 & 24.1 & 28.7 & 42.2 & 26.3 & 28.7 \\
\hline September & 32.5 & 19.0 & 61.5 & 33.4 & 19.2 & 65.4 & 38.8 & 23.6 & 32.3 & 39.4 & 24.7 & 31.3 \\
\hline October & 30.3 & 16.2 & 61.8 & 30.7 & 17.0 & 58.5 & 35.9 & 20.3 & 35.3 & 37.3 & 21.4 & 36.0 \\
\hline
\end{tabular}

Cultivars and management practices

The 100 cultivars (indica and japonica types) were selected from core collection genetically diverse genotypes introduced from different countries. Direct seeding planting method was used (seedling establishment in dry soil) for the stress conditions while, transplanting to plots of seven rows by five meters long was used for non-stress conditions. Heat stress and non-stress trials were laid out in a randomized complete block design with three replications. The nonstress trials were sown on 5 May, 2009 while, for the heat stress trials, seeding dates (20 May, 2009) based on flowering data were followed. All agronomic practices were applied at the optimum level.

\section{Data recorded and analysis}

Data were recorded for number of days to heading, plant height, panicle length, no. panicles/plant, 100 -grain weight, pollen sterility \%, spikelet sterility, and grain yield using the middle rows of each plot. Pollen sterility was determined using 10 spikelets from the top, middle, and bottom portions of main panicles of three plants, i.e. 30 spikelets per plot. One anther each from the 30 spikelets were taken and mixed, crushed, and stained in a glass slide. Fertile and 
sterile pollen were counted using a microscope at 10X magnification and three microscope fields. Five main panicles were used for assessing spikelet sterility. Each panicle was divided into top and bottom portions, then filled and unfilled spikelets were counted separately for each portion. Data of percentage spikelet sterility/fertility were obtained at harvest using the main panicle. Grain yield was measured and adjusted to $14 \%$ moisture content. All data were analysed using programs of SAS version 9.1 (SAS Institute Inc., 2003).

\section{Results and Discussion}

The pattern of flowering and hence the total number of spikelet's that reached anthesis per day (Table 2) differed significantly between genotypes and in response to temperature. Days to heading of the cultivars in the non- stress (NS) trials ranged from 88.00 to 120.00 day at Sakha conditions (Sakha Research Station) and from 67.00 to 109.00 day at New Valley Research Station, with the maximum/minimum temperatures at $33.5 / 23^{\circ} \mathrm{C}$ and $38.4 / 28.5^{\circ} \mathrm{C}$, as a mean daily heat temperature in the experimental period during 2009 and 2010 seasons, respectively. Thus, the cultivars subjected to higher temperature stress in the heat stress (HS) significantly delayed than in the non - stress (NS).

TABLE 2. Mean performance for the studied traits of the best selected varieties under both stress and non-stress conditions (Mean of 2009 and 2010 seasons).

\begin{tabular}{|l|c|c|c|c|c|c|c|c|}
\hline \multirow{2}{*}{ Varieties } & \multicolumn{2}{|c|}{$\begin{array}{c}\text { Days to heading } \\
\text { (days) }\end{array}$} & \multicolumn{2}{c|}{$\begin{array}{c}\text { Plant height } \\
(\mathbf{c m})\end{array}$} & \multicolumn{2}{c|}{$\begin{array}{c}\text { Panicle length } \\
(\mathbf{c m})\end{array}$} & $\begin{array}{c}\text { No. of panicles/ } \\
\text { plant }\end{array}$ \\
\cline { 2 - 9 } & HS & NS & HS & NS & HS & NS & HS & NS \\
\hline Kasalath & 96.00 & 106.00 & 90.00 & 100.00 & 19.00 & 22.00 & 19.00 & 22.00 \\
\hline Shoni & 105.00 & 115.00 & 95.00 & 105.00 & 14.00 & 18.00 & 25.00 & 27.00 \\
\hline Tupa & 103.00 & 113.00 & 98.00 & 112.00 & 19.00 & 20.00 & 11.00 & 17.00 \\
\hline ARC 7047 & 100.00 & 120.00 & 90.00 & 90.00 & 19.00 & 18.00 & 16.00 & 19.00 \\
\hline ARC 11094 & 100.00 & 112.00 & 90.00 & 100.00 & 18.00 & 20.00 & 21.00 & 23.00 \\
\hline RyoSuisanKoumai & 90.00 & 98.00 & 98.00 & 104.00 & 19.00 & 19.00 & 14.00 & 18.00 \\
\hline Asu & 109.00 & 120.00 & 85.00 & 92.00 & 19.00 & 19.00 & 15.00 & 19.00 \\
\hline Vary Futsi & 102.00 & 110.00 & 80.00 & 115.00 & 19.00 & 23.00 & 17.00 & 23.00 \\
\hline Pinulupot 1 & 100.00 & 108.00 & 100.00 & 120.00 & 17.00 & 24.00 & 21.00 & 26.00 \\
\hline Tupa 729 & 75.00 & 88.00 & 110.00 & 122.00 & 20.00 & 20.00 & 21.00 & 26.00 \\
\hline Urasan 1 & 100.00 & 110.00 & 100.00 & 110.00 & 19.00 & 19.00 & 16.00 & 20.00 \\
\hline Aikoku & 67.00 & 97.00 & 85.00 & 90.00 & 17.00 & 20.00 & 19.00 & 19.00 \\
\hline Shinriki & 97.00 & 107.00 & 105.00 & 110.00 & 18.00 & 19.00 & 20.00 & 24.00 \\
\hline Kameji & 77.00 & 100.00 & 112.00 & 116.00 & 17.00 & 22.00 & 20.00 & 20.00 \\
\hline Kahei & 99.00 & 105.00 & 103.00 & 117.00 & 21.00 & 19.00 & 18.00 & 22.00 \\
\hline Dee geo woo gen & 97.00 & 100.00 & 68.00 & 85.00 & 17.00 & 19.00 & 18.00 & 15.00 \\
\hline Ao gou 8 & 101.00 & 104.00 & 80.00 & 95.00 & 18.00 & 24.00 & 22.00 & 27.00 \\
\hline Taichung Native 1 & 100.00 & 113.00 & 82.00 & 93.00 & 21.00 & 21.00 & 20.00 & 20.00 \\
\hline Guizhao 2 & 88.00 & 98.00 & 75.00 & 85.00 & 18.00 & 18.00 & 16.00 & 21.00 \\
\hline Giza 178 & 95.00 & 100.00 & 85.00 & 100.00 & 23.25 & 25.25 & 22.33 & 25.00 \\
\hline LSD (0.05) & $\mathbf{4 . 1 0}$ & $\mathbf{3 . 5 0}$ & $\mathbf{3 . 3 0}$ & $\mathbf{2 . 3 0}$ & $\mathbf{1 . 8 0}$ & $\mathbf{1 . 3 5}$ & $\mathbf{3 . 0 0}$ & $\mathbf{2 . 3 6}$ \\
\hline
\end{tabular}

Egypt. J. Agron. 33, No. 2 (2011) 
TABLE 2. Cont.

\begin{tabular}{|c|c|c|c|c|c|c|c|c|}
\hline \multirow[t]{2}{*}{ Varieties } & \multicolumn{2}{|c|}{$\begin{array}{c}\text { Sterility } \\
(\%)\end{array}$} & \multicolumn{2}{|c|}{$\begin{array}{c}\text { Pollen sterility } \\
(\%)\end{array}$} & \multicolumn{2}{|c|}{$\begin{array}{l}100 \text { grain } \\
\text { weight }(\mathrm{g})\end{array}$} & \multicolumn{2}{|c|}{$\begin{array}{c}\text { Grain yield } \\
\text { (ton/ha) }\end{array}$} \\
\hline & HS & NS & HS & NS & HS & NS & HS & NS \\
\hline Kasalath & 60.00 & 11.00 & 44.00 & 29.00 & 2.30 & 2.44 & 6.50 & 7.50 \\
\hline Shoni & 65.00 & 15.00 & 35.00 & 30.00 & 2.20 & 2.32 & 7.14 & 8.00 \\
\hline Tupa & 35.00 & 18.00 & 45.00 & 32.00 & 2.30 & 2.40 & 6.18 & 7.60 \\
\hline ARC 7047 & 30.00 & 17.00 & 52.00 & 16.00 & 2.40 & 2.55 & 6.42 & 9.50 \\
\hline ARC 11094 & 18.00 & 10.00 & 22.00 & 18.00 & 2.50 & 3.00 & 8.80 & 10.50 \\
\hline RyoSuisanKoumai & 40.00 & 18.00 & 55.00 & 33.00 & 2.30 & 2.50 & 5.95 & 8.33 \\
\hline Asu & 40.00 & 16.00 & 50.00 & 23.00 & 2.30 & 2.30 & 5.95 & 8.00 \\
\hline Vary Futsi & 25.00 & 15.00 & 52.00 & 27.00 & 2.30 & 2.30 & 6.18 & 9.00 \\
\hline Pinulupot 1 & 16.00 & 10.00 & 15.00 & 22.00 & 2.30 & 2.50 & 8.09 & 9.75 \\
\hline Tupa 729 & 25.00 & 17.00 & 18.00 & 32.00 & 2.20 & 2.55 & 7.37 & 8.35 \\
\hline Urasan 1 & 28.00 & 16.00 & 33.00 & 24.00 & 2.30 & 2.45 & 7.14 & 9.10 \\
\hline Aikoku & 18.00 & 18.00 & 32.00 & 34.00 & 2.30 & 2.30 & 7.14 & 8.60 \\
\hline Shinriki & 35.00 & 14.00 & 24.00 & 25.00 & 2.20 & 2.38 & 7.61 & 8.20 \\
\hline Kameji & 23.00 & 13.00 & 28.00 & 23.00 & 2.10 & 2.30 & 7.37 & 9.30 \\
\hline Kahei & 80.00 & 18.00 & 48.00 & 17.00 & 2.50 & 2.80 & 5.42 & 8.40 \\
\hline Dee geo woo gen & 10.00 & 13.00 & 38.00 & 22.00 & 2.40 & 2.40 & 6.66 & 8.00 \\
\hline Ao gou 8 & 34.00 & 14.00 & 54.00 & 25.00 & 2.50 & 2.50 & 7.14 & 8.35 \\
\hline Taichung Native 1 & 14.00 & 14.00 & 50.00 & 23.00 & 2.10 & 2.50 & 6.18 & 8.33 \\
\hline Guizhao 2 & 80.00 & 18.00 & 47.00 & 28.00 & 2.10 & 2.50 & 6.42 & 8.30 \\
\hline Giza 178 & 15.00 & 9.00 & 25.00 & 22.00 & 2.30 & 2.30 & 7.20 & 11.40 \\
\hline $\operatorname{LSD}(0.05)$ & 7.00 & 7.00 & 0.44 & 0.50 & 0.18 & 0.25 & 0.20 & 0.20 \\
\hline
\end{tabular}

With respect to plant height, the values ranged between $85 \mathrm{~cm}$ for Guzho2 and $122 \mathrm{~cm}$ for Kameji comparing with the check varieties Giza $178(100 \mathrm{~cm})$, (Table 2). The most desirable mean values towards dwarfing were obtained from the genotypes Deegeowoo gen $(85 \mathrm{~cm})$, Guizhao2 $(85 \mathrm{~cm})$, Aikoku $(90 \mathrm{~cm})$, ARC707 $(90 \mathrm{~cm})$ and Asu $(92 \mathrm{~cm})$. While the mean values for the plant height ranged between $68 \mathrm{~cm}$ in Deegeowoo gen and $112 \mathrm{~cm}$ in Kameji, indicating that heat stress affected severely on plant height.

For panicle length, Giza 178 followed by Ao gou 8, Pinulupot 1 and Vary Futsi rice genotypes reached the longest panicles, while, Shoni, ARC 7047, Guizhao 2 was found to have the shortest panicle comparing with other cultivated genotypes under non-stress condition. On the contrary, Giza 178, Taichung Native1 and Kahei were the longest panicle comparing with other cultivated genotypes under heat stress condition (Table 2). 
Regarding number of panicles/plant, the studied genotypes ranged from 11.00-25.00 and from 15.00-27.00 under heat and normal conditions, respectively. The highest number of panicles/plant occurred in the case of the genotypes Shoni, ARC11094, Pinulupot1, Tupa 729, Shinriki, Ao Gou 8 and Giza 178 under both normal and heat stress conditions. The mean values for number of panicles of these genotypes ranged between 20.00-25.00 and 23.0027.00 under heat and normal conditions, respectively. This result indicates that these genotypes would be more able to recover after a period of stress. Heat stress during vegetative growth causes many physiological and metabolic changes, including alterations in hormone homeostasis. Some of the heat-induced processes at the cell, organ and whole-plant levels may be hormone regulated; others may be the consequence of a new hormonal status, altered by heat stress (Matsui \& Omasa, 2002).

For 100-grain weight given in Table 2, the analysis of variance showed that significant differences among genotypes were detected under each condition. The highest values of 100-grain weight were obtained for the genotypes ARC11094, Kahei, and Ao Gou 8, and significant differences were observed between normal and heat conditions for this trait. The mean values were ranged from 2.10 to 2.50 and from 2.50 to 3.00 grams for heat and normal conditions, respectively. Grain filling is the final stage of growth in cereals, where fertilized ovaries develop into caryopses. Its duration and rate determine the final grain weight, a key component of the total yield. High temperature is the major stress factor during the maturation and ripening of rice in many production areas. Periods of high temperature during grain development cause large yield losses in cereals. This reduction is mainly caused by a reduction in starch accumulation, because, in general, over $65 \%$ of cereal dry weight (DW) is related to starch. The reduction in 100 grain weight in response to heat stress during the early periods of grain filling can mainly be attributed to the lower number of endosperm cells, while during the later stages stress results in the impairment of starch synthesis either because of the limited supply of assimilates for the grain or the direct effects on the biosynthesis processes in the grain. It could be concluded that hightemperature stress during the vegetative and reproductive growth phases caused greater reduction in grain yield as compared with that during the ripening phase, which caused low reduction in grain yield. Among yield components, the number of panicles/plant and grains/panicle showed greater sensitivity to hightemperature stress, whereas 1000-grain weight was less affected by the same level of heat stress. The marked reduction in grain yield of rice under hightemperature stress during vegetative growth was mainly attributed to the significant reduction in the number of panicles/plant followed by the number of grains/panicle. The reduction in grain yield by high-temperature stress during the reproductive growth phase was caused by significant decreases in the number of panicles/plant and number of grains/ panicle and the marginal reduction in 1,000grain weight. However, the relatively low reduction in grain yield due to heat stress during ripening was probably caused by the small reduction in 1000-grain weight and the number of grains per panicle.

Egypt. J. Agron. 33, No. 2 (2011) 
Spikelet sterility under heat stress (HS) ranged from $10 \%$ to $80 \%$ at New Valley Research Station (NVRS) and 8 to $18 \%$ at Sakha Research Station (SRS) and averaged 34\% at New Valley Research Station (NVRS) and 9\% at SRS. On average, spikelet sterility in heat stress (HS) trials increased by $80 \%$ at NVRS and $15 \%$ at SRS. The lowest spikelet sterilities under HS were observed in Dee geo woo gen, Taichung Native 1 and Giza 178 (10, 14 and $15 \%$, respectively). Flowering (anthesis and fertilization), and to a lesser extent booting (microsporogenesis), are the most susceptible stages of development to temperature in rice (Satake \& Yoshida, 1978 and Farrell et al., 2006). Previous studies, summarized in Satake \& Yoshida (1978), had shown that spikelets at anthesis that are exposed to temperatures $>35^{\circ} \mathrm{C}$ for about 5 days during the flowering period are sterile and set no seed. Sterility is caused by poor anther dehiscence and low pollen production, and hence low numbers of germinating pollen grains on the stigma (Matsui et al., 2000, 2001 and Prasad et al., 2006). There is genotypic variation in spikelet sterility at high temperature (Matsui et al., 2001; Satake \& Yoshida, 1978 and Prasad et al., 2006) that can be defined by different temperature thresholds (Nakagawa et al., 2002). It has been suggested that indica sp. are more tolerant to higher temperatures than japonica sp. (Satake \& Yoshida, 1978 and Matsui et al., 2000), although heat tolerant genotypes have been found in both subspecies.

Pollen sterilities in heat stress (HS) and non- stress (NS) trials averaged $38.35 \%$ and $24.10 \%$ at New Valley Research Station (NVRS) and Sakha Research Station (SRS), respectively, which was 38\% higher relative those of NS trial. The lowest pollen sterilities under heat stress (HS) were observed in the variety Pinulupot 1 (15\%), Tupa $729(18 \%)$, ARC 11094 (22\%) and Giza 178 (25\%). The genotypes ARC 7047 (16\%), Kahei (17\%) and ARC 11094 (18\%) gave the lowest average pollen sterilities under normal conditions. Horie et al. (1996) suggested that the anticipated high temperature would induce floret sterility and increase the instability of rice yield. They also showed that adoption of high temperature tolerant cultivars is one of the most effective countermeasures to maintain high productivity and stability of rice under temperate region.

Analyses of variances revealed significant to highly significant differences among the cultivars for all traits in both NS and HS trials. Grain yield under HS ranged from 5.42 ton/ha to 8.80 ton/ha at NVRS and from 7.50 to 11.40 ton/ha at SRS, representing an average yield reduction relative to NS trials of $35 \%$ and $33 \%$, respectively, at the two locations. ARC 11094 followed by Pinulupot 1 varieties produced the highest yield under HS condition ( 8.80 and 8.09 ton/ha, respectively). Kahei, Ryo Suisan Koumai and Asu varieties had the lowest yield of 5.42, 5.95 and 5.95 ton/ha, respectively. Meanwhile, Giza 178 produced the highest yield under normal condition (11.40 ton/ha). High-temperature stress during the vegetative and reproductive growth phases caused greater reduction in grain yield as compared with non-stress conditions, which showed $28 \%$ to $33 \%$ reduction in grain yield, respectively. Among yield components, the number of 
panicles/plant and grains/panicle showed greater sensitivity to high-temperature stress, whereas 100 grain weight was less affected by the same level of heat stress. The marked decrease in grain yield of rice under high-temperature stress during vegetative growth was mainly attributed to the significant reduction in the number of panicles/plant followed by the number of grains/ panicle as well as 100 grain weight.

Data from Table 2 show that 20 of 100 tested genotypes have desirable values for various traits. The varieties ARC 11094, Pinulupotl1, Tupa729, Shinriki, Kameji and Giza 178 were superior for most of the studied traits under heat conditions especially for yield and shoot characters. Thus, these genotypes partially proved to be good candidates for heat tolerance.

The analysis of variance showed significant differences amongst the genotypes for all characters and expressed considerable range of variation. It is also observed that phenotypic and genotypic variance (Table 3) exhibited the same trend of variability. The maximum range of variation was observed for plant height, 100-grain weight and grain yield for the genetic improvement in these characters.

TABLE 3. Heritability in broad sense and coefficient of variability estimates for the characters studied.

\begin{tabular}{|l|c|c|c|}
\hline \multirow{2}{*}{ Traits } & \multicolumn{2}{c|}{ Variance components } & \multirow{2}{*}{ Heritability \% } \\
\cline { 2 - 3 } & Genotypic & Phenotypic & \\
\hline Days to heading(day) & 23 & 32 & 71.87 \\
\hline Plant height(cm) & 125 & 140 & 89.82 \\
\hline Panicle length (cm) & 48 & 70 & 68.75 \\
\hline No. of panicles/plant & 35 & 43 & 81.39 \\
\hline Sterility \% & 22 & 28 & 78.75 \\
\hline Pollen sterility\% & 55 & 86 & 63.95 \\
\hline 100 grain weight(g) & 0.009 & 0.011 & 81.81 \\
\hline Grain yield(ton/ha) & 65 & 75 & 86.66 \\
\hline
\end{tabular}

Correlations among grain yield, spikelet sterility, pollen sterility, and 100 grain weight under both non-stress and heat stress conditions are shown in Table 4. In HS conditions, grain yield under heat stress conditions was negatively correlated with pollen sterility under heat stress conditions $\left(-0.40^{*}\right)$ but it was positively correlated with grain yield under non-stress conditions $\left(0.55^{*}\right)$, spikelet sterility under non-stress conditions $\left(0.52^{*}\right)$ and 100 grain weight under both heat and non-stress conditions $\left(0.65^{*}\right.$ and $78^{*}$, respectively). Grain yield

Egypt. J. Agron. 33, No. 2 (2011) 
under non-stress was negatively correlated with sterility \% under heat stress $\left(-0.48^{*}\right)$, pollen sterility under heat stress conditions $\left(-0.55^{*}\right)$, while, it was positively correlated with 100 grain weight under both non-stress and stress conditions $\left(0.72^{*}\right.$ and $0.66^{*}$, respectively). Pollen sterilities in HS and NS trials were positively correlated $\left(0.70^{*}\right)$.

TABLE 4. Correlation of grain yield and the other studied characters under both stress and non-stress conditions.

\begin{tabular}{|l|l|l|l|l|l|l|l|}
\hline Characters & GY HS & GY NS & SS HS & SS NS & PS HS & PS NS & 100 HS \\
\hline GYNS & $0.82^{*}$ & - & & & & & \\
\hline SS HS & -0.28 & $-0.48^{*}$ & & & & & \\
\hline SS NS & $0.52^{*}$ & 0.25 & 0.22 & & & & \\
\hline PS HS & $-0.40^{*}$ & $-0.55^{*}$ & 0.15 & 0.11 & & & \\
\hline PS NS & -0.11 & -0.18 & 0.20 & 0.19 & $0.74^{*}$ & & \\
\hline 100 HS & 0.65 & $0.72^{*}$ & 0.18 & 0.23 & 0.26 & 0.10 & \\
\hline 100 NS & 0.78 & $0.66^{*}$ & 0.11 & 0.27 & 0.18 & 0.30 & 0.22 \\
\hline
\end{tabular}

GY HS=grain yield under heat stress, GY NS= grain yield under non-stress conditions, SS HS= spikelet sterility under heat stress, SS NS= spikelet sterility under non-stress conditions, PS $\mathrm{HS}=$ pollen sterility under heat, PS NS=pollen sterility under non-stress conditions, $100 \mathrm{HS}=100$ grain weight under heat and $100 \mathrm{NS}=100$ grain weight under non-stress conditions.

Increasing the heat tolerance of rice at flowering, one of the most sensitive stages of development to stress, is a vital adaptation strategy for variable and warmer climates (Horie et al., 1996). Tolerance classically comprises elements of escape, i.e. the timing of panicle emergence and spikelet/floret opening relative to the occurrence of the stress and the absolute tolerance to stress of key processes, such as anther dehiscence. It is essential for phenotyping and modelling that these two mechanisms, as well as the effects of temperature on the rate of spikelet anthesis, are clearly differentiated.

\section{Conclusion}

High temperature stresses appreciably affect the performance of rice genotypes and related selection progress for yield improvement. In this investigation, based on the results obtained there was inconsistent performance for the characters studied over two contrasting environments (normal and heat conditions). All evaluated genotypes possessed a wide range of most of the studied characters. Breeding rice varieties tolerant to high temperature has so far received little attention. The genotypes Shoni, Ao Gou8 and Giza 178 were clearly the most heat tolerant of the genotypes studied, with from (22-25) panicles/plant, from (2.00-2.50) 100- grain weight, and from 15-34\% sterility compared with the others. So some of these genotypes can be used as a donor parents in rice breeding program by crossing with local varieties which having high yield potential, to combine heat tolerance with high yield traits. 


\section{References}

Collard, B.C.Y. and Mackill D.J. (2008) Marker-assisted selection: an approach for precision plant breeding in the twenty-first century. Phil. Trans. R. Soc. B 363, 557.

Craufurd, P.Q., Prasad, P.V.V., Kakani, V.G., Wheeler, T.R. and Nigam, S.N. (2003) Heat tolerance in groundnut. Field Crops Res. 80, 63-77.

Farrell, T.C., Fox, K.M., Williams, R.L. and Fukai, S. (2006) Genotypic variation for cold tolerance during reproductive development in rice: screening with cold air and cold water. Field Crops Research, 98, 178-194.

Horie, T., Matsui, T., Nakagawa, H. and Omasa, K. (1996) Effect of elevated $\mathrm{CO}_{2}$ and global climate change on rice yield in Japan. "Climate Change and Plant in East Asian”. Tokyo: Springer-Verlag, pp.39-56.

Jagadish, S.V.K., Craufurd, P.Q. and Wheeler, T.R. (2007) High temperature stress and spikelet fertility in rice (Oryza sativa L.). J. Expt. Botany, 58, 1627-1635.

Kijne, J.W. (2003) Water productivity under saline conditions. In: "Limits and Opportunities for Improvement”. Kijne (Ed), CABI,Wallingford, p. 89.

Mackill, D.J. and Coffman. W.R. (1983) Inheritance of high temperature tolerance and pollen shedding in rice cross. Z Pflanzesuchtg, 91, 61-69.

Matsui, T., Omasa, K. and Horie, T. (2000) High temperature at flowering inhibit swelling of pollen grains, a driving force for thecae dehiscence in rice (Oryza sativa L.). Plant Production Science, 3, 430-434.

Matsui, T. and Omasa, K. (2002) Rice (Oryza sativa L.) cultivars tolerant to high temperature at flowering: anther characteristics. Ann. Bot. 89, 683-687.

Matsui, T., Tomasa, K. and Horie, T. (2001) The difference in sterility due to high temperature during the flowering period among japonica rice varieties. Plant Prod. Sci. 3, 430-434.

Mohammed, A.R., and Tarpley, L. (2009) High night time temperatures affect rice productivity through altered pollen germination and spikelet fertility. Agric. Forest Meteorology, 149, 999-1008.

Nakagawa, H., Horie, T. and Matsui, T. (2002) Effects of climate change on rice production and adaptive technologies. In: "Rice Science: Innovations and Impact for Livelihood”. Mew, T.W., Brar, D.S., Peng, S., Dawe, D., Hardy, B. (Ed.) pp. 635-657. China: International Rice Research Institute.

Prasad, P.V.V., Boote, K.J., Allen Jr., L.H., Sheehy, J.E. and Thomas, J.M.G. (2006) Species, ecotype and cultivar differences in spikelet fertility and harvest index of rice in response to high temperature stress. Field Crop Res. 95, 398-411.

Redoña, E.D., Laza, M.A. and Manigbas, N.L. (2007) Breeding rice for adaptation and tolerance to high temperatures. In: Proc. Intl . Workshop on Cool Rice for a Warmer World, Huazhong Agricultural University, March 2007.Wuhan, Hubei, China, pp.26-30

Egypt. J. Agron. 33, No. 2 (2011) 
SAS (2003) SAS Institute Inc., Cary, North Carolina, USA.

Satake, T. and Yoshida, S. (1978) High temperature induced sterility in indica rices at flowering. Jap. J. Crop Sci. 47, 6-17.

Singh, S. (2001) Growth, yield and biochemical response of rice genotypes to low light and high temperature-humidity stress. Oryza, 37(1), 35-38.

Wahid, A., Gelani, S., Ashraf, M. and Foolad, M.R.( 2007) Heat tolerance in plants: An overview. Environmental and Experimental Botany, 82, 199-223.

Weerakoon, W.M.W., Maruyama, A. and Ohba, K. (2008) Impact of humidity on temperature induced grain sterility in rice (Oryza sativa L). J. Agron. Crop Sci. 194, 135-140.

Yoshida, S., Satake, T. and Mackill, D.J. (1981) High temperature stress in rice. IRRI Res. Paper Series 67. IRRI, Los Banos, Philippines.

(Received 10/1/2012;

accepted 10/6/2012) 


\section{تحديد التراكيب الوراثية للأرز المتحملة للحرارة المرتفعة تحت الظروف الحقلية

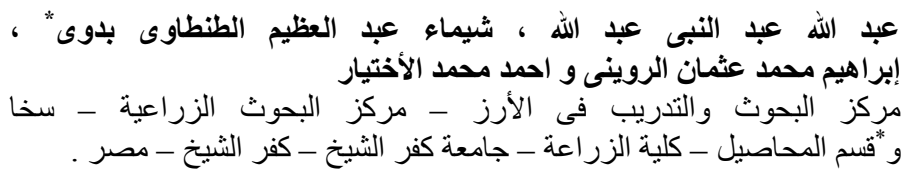

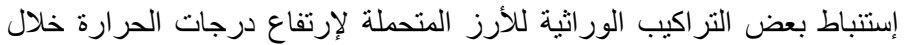

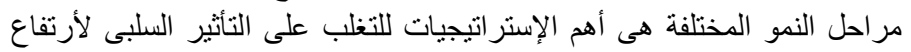

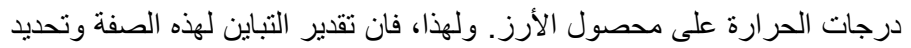

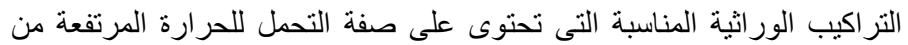

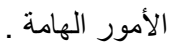

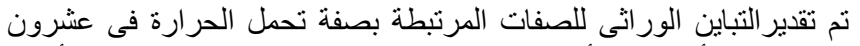

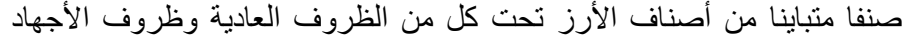

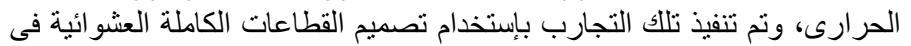

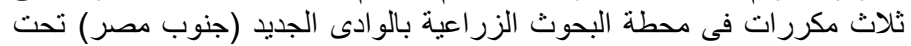

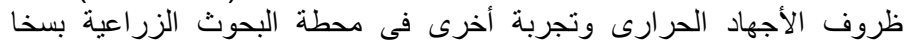
(شمال مصر) تحت الظروف العادية.

أوضحت النتائج وجود تباين واضح بين التراكيب الوراثية المستخدمة فى الثى

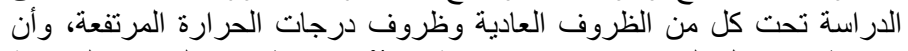

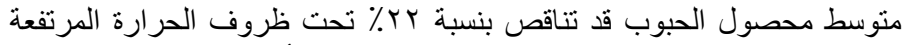

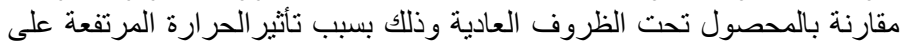

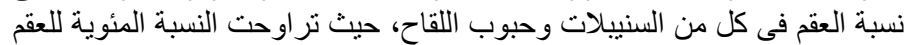

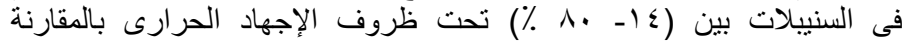

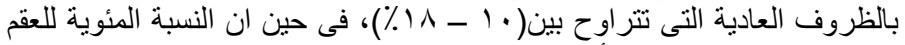

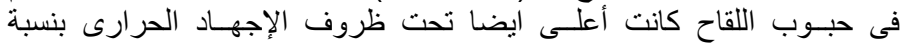

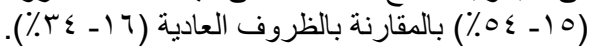

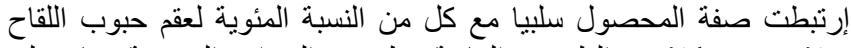

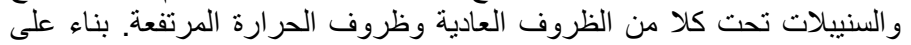

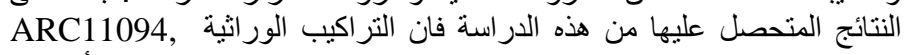
Pinulupot1, Tupa729, Shinriki, Kameji and Giza 178 متحملة للحرارة. 